\title{
Simplex lattice design for optimization of the mass ratio of Curcuma longa L., Curcuma zedoaria (Christm.) Roscoe and Curcuma aromatica Salisb. to maximize curcuminoids content and antioxidant activity
}

\author{
CHAOWALIT MONTON* \\ PANUPONG CHUANCHOM \\ PUWADON POPANIT \\ SUKANYA SETTHARAKSA \\ PATHAMAPORN PATHOMPAK \\ Drug and Herbal Product Research \\ and Development Center \\ College of Pharmacy, Rangsit University, \\ Pathum Thani 12000, Thailand
}

Accepted August 15, 2020

Published online August 26, 2020

\begin{abstract}
The aim of this work was to optimize the mass ratio of three Curcuma plants' rhizomes to obtain the highest curcuminoid content and antioxidant activity using the simplex lattice design. The selected Curcuma plants were C. longa, C. zedoaria and $C$. aromatica. The simplex lattice design was applied in the work. The individual curcuminoids (curcumin, demethoxycurcumin and bis-demethoxycurcumin) and total curcuminoid content were determined using high-performance liquid chromatography. Curcuma longa alone provided the highest content of bis-demethoxycurcumin and demethoxycurcumin. A mixture of $C$. longa and C. aromatica in the mass ratio of $72: 28 \%$ provided the highest curcumin content. The results showed that $C$. longa alone exhibited the highest antioxidant activity.
\end{abstract}

Keywords: Curcuma, curcuminoids, HPLC, simplex lattice design, optimization, antioxidant activity

Curcuma longa L., Curcuma zedoaria (Christm.) Roscoe and Curcuma aromatica Salisb. are plants belonging to the Zingiberaceae family. The most extensively used parts of these three plants are the rhizomes. According to the Thai Herbal Pharmacopoeia (1), C. longa is used as stomachic, carminative, coloring agent and adstringent, whereas $C$. zedoaria is used as stomachic, antidiarrheal and emmenagogue. C. longa has several biological and pharmacological activities such as antioxidant, antiinflammatory, antiangiogenic and antiapoptotic (2). Additionally, it also exhibits antihyperlipidemic, anti-Alzheimer, antidepressant, antidiabetic, radioprotective and antimicrobial activities (3). C. aromatica exhibits antiinflammatory, wound healing, antitumor, anticancer, mosquito repellent, antiplatelet, antitussive, antioxidant, antimelanogenic and antinephrotoxic activities (4).

All three plants exhibit antioxidant activity, that can protect the skin. Curcuminoids, including curcumin (CUR), demethoxycurcumin (DMC), and bis-demethoxycurcumin $(\mathrm{BDMC})$, are the major chemical constituents in their rhizomes (5). Among these three curcuminoids, CUR is the most abundant and its mechanism of antioxidant activity has been described $(6,7)$. CUR can defend biomembranes from peroxidative damage by scav-

*Correspondence; e-mail: chaowalit@rsu.ac.th 
C. Monton et al.: Simplex lattice design for optimization of the mass ratio of Curcuma longa L., Curcuma zedoaria (Christm.) Roscoe and Curcuma aromatica Salisb. to maximize curcuminoids content and antioxidant activity, Acta Pharm. 71 (2021) $445-457$.

enging the reactive free radicals. CUR can degrade into several compounds, i.e., trans-6(4'-hydroxy-3'-methoxyphenyl)-2,4-dioxo-5-hexanal, ferulic aldehyde, ferulic acid, ferruloyl methane and vanillin (8). Ferulic acid and vanillin exhibit antioxidant activity as well (9). Another work has also proven that CUR reveals a good antioxidant activity in several in vitro assays (10). In addition, DMC and BDMC also exhibit antioxidant activity (11).

The authors attempt is to distinguish the effect of the mass ratio of C. longa, C. zedoaria and C. aromatica rhizome powder on the content of curcuminoids and antioxidant activity, to further develop as an ingredient in the skincare formulations, using the simplex lattice design.

\section{EXPERIMENTAL}

\section{Materials}

Three standard curcuminoids (purity $\geq 99 \%$ ), i.e., BDMC, DMC and CUR were purchased from Chengdu Biopurify Phytochemicals Ltd., China. DPPH (2,2-diphenyl-1-picrylhydrazyl) was purchased from Sigma-Aldrich Inc., USA. Absolute ethanol was purchased from QRëC, New Zealand. Acetonitrile (HPLC grade) was purchased from Honeywell-Burdick \& Jackson, USA. Acetic acid (AR grade) was purchased from CarloErba, France.

\section{Plant samples and extraction procedure}

The rhizomes of C. longa, C. zedoaria and C. aromatica were collected from Buached District, Surin Province, Thailand. C. longa and C. aromatica were collected in November 2017, while C. zedoaria was collected in January 2018. The voucher specimens CM-

Table I. Coded and actual value of the model conditions obtained from simplex lattice design

\begin{tabular}{ccccccc}
\hline \multirow{2}{*}{ Condition } & & Coded value & \multicolumn{4}{c}{ Actual value (mass of dried rhizome powder, g) } \\
\cline { 2 - 7 } & $x_{1}$ & $x_{2}$ & $x_{3}$ & C. longa & C. zedoaria & C. aromatica \\
\hline 1 & 1 & 0 & 0 & 30 & 0 & 0 \\
2 & 0 & 1 & 0 & 0 & 30 & 0 \\
3 & 0 & 0 & 1 & 0 & 0 & 30 \\
4 & 0.5 & 0.5 & 0 & 15 & 15 & 0 \\
5 & 0.5 & 0 & 0.5 & 15 & 0 & 15 \\
6 & 0 & 0.5 & 0.5 & 0 & 15 & 15 \\
7 & 0.67 & 0.17 & 0.17 & 20 & 5 & 5 \\
8 & 0.17 & 0.67 & 0.17 & 5 & 20 & 5 \\
9 & 0.17 & 0.17 & 0.67 & 5 & 5 & 20 \\
10 & 0.33 & 0.33 & 0.33 & 10 & 10 & 10 \\
11 & 0.33 & 0.33 & 0.33 & 10 & 10 & 10 \\
12 & 0.33 & 0.33 & 0.33 & 10 & 10 & 10 \\
\hline
\end{tabular}


C. Monton et al.: Simplex lattice design for optimization of the mass ratio of Curcuma longa L., Curcuma zedoaria (Christm.) Roscoe and Curcuma aromatica Salisb. to maximize curcuminoids content and antioxidant activity, Acta Pharm. 71 (2021) $445-457$.

CL001-1-11-2017, CM-CZ001-1-01-2018, and CM-CA002-2-11-2017 were coded for C. longa, C. zedoaria and C. aromatica, resp. (Drug and Herbal Product Research and Development Center, College of Pharmacy, Rangsit University).

Rhizomes of each plant were cleaned, sliced and sun-dried for 3 days. The dried rhizomes were pulverized and passed through a $0.841-\mathrm{mm}$ (20-mesh) sieve. The $30 \mathrm{~g}$ of rhizome powder was extracted in an ultrasonic bath for $20 \mathrm{~min}$ at different mass ratios (Table I) using $100 \mathrm{~mL}$ of absolute ethanol. The extract was separated from the marc after vacuum filtration. The extraction was performed in triplicate; three filtrates were pooled and the solvent was removed by a rotary evaporator.

\section{High-performance liquid chromatography (HPLC) conditions}

HPLC method, which was already reported, has been adapted and preliminarily validated $(13,19)$. Agilent 1260 Infinity HPLC instrument (Agilent Technologies, USA) was used in the analysis. ACE Generix column, $150 \times 4.6 \mathrm{~mm}, 5 \mu \mathrm{m}$ (Advanced Chromatography Technologies Ltd, UK) was used. An isocratic system composed of acetonitrile/acetic acid $(1 \%)$ in a volume ratio of 55:45, was used at a flow rate of $1 \mathrm{~mL} \mathrm{~min}{ }^{-1}$. The temperature of the column was set at $30^{\circ} \mathrm{C}$. The injection volume was $10 \mu \mathrm{L}$. The response was detected at $425 \mathrm{~nm}$ by a photodiode array detector.

\section{HPLC method preliminary validation}

HPLC method validation was done according to ICH guidelines (12). The five topics, including linearity and range, selectivity, the limit of detection $(L O D)$ and limit of quantitation $(L O Q)$, precision and accuracy were demonstrated.

Linearity and range. - A stock solution of each BDMC, DMC and CUR in the concentration of $1000 \mu \mathrm{g} \mathrm{mL} \mathrm{m}^{-1}$ was prepared. Methanol was used as the solvent. The mixtures of three standard curcuminoids for each standard were prepared from the stock solutions at five concentration levels (i.e., 10, 25, 50, 75, and $100 \mu \mathrm{g} \mathrm{mL} \mathrm{L}^{-1}$ ). Two sets of mixtures of three standard curcuminoids were prepared. They were filtered using a nylon syringe filter and injected into the HPLC instrument. Each concentration was analyzed in triplicate. The calibration curves for each BDMC, DMC and CUR were constructed. The linear equation, coefficient of determination $\left(R^{2}\right)$, and range were reported.

Selectivity. - Selectivity was evaluated based on the selectivity ratio and chromatographic resolution. The selectivity ratio was calculated from the capacity factor values of the two peaks.

LOD and LOQ. - The standard solution was diluted with methanol. The $L O D$ and $L O Q$ were estimated based on the signal-to-noise ratio of 10:1 and 3:1, resp.

Precision. - Three concentration levels of each standard curcuminoid $(25,50$, and $75 \mu \mathrm{g}$ $\mathrm{mL}^{-1}$ ) were analyzed. The analysis, done within-a-day and on three days, was used to calculate the percent relative standard deviation (RSD). These data were reported as intraday and inter-day precision, resp.

Accuracy. - The individual three concentration levels of each standard curcuminoids $\left(25,50\right.$ and $\left.75 \mu \mathrm{g} \mathrm{mL}^{-1}\right)$ were added to the extract (condition 10) solution. Each concentration level was analyzed in triplicate and the accuracy of each concentration level was reported. 
C. Monton et al.: Simplex lattice design for optimization of the mass ratio of Curcuma longa L., Curcuma zedoaria (Christm.) Roscoe and Curcuma aromatica Salisb. to maximize curcuminoids content and antioxidant activity, Acta Pharm. 71 (2021) $445-457$.

\section{Analysis of curcuminoids content}

The plant extract was diluted with methanol to a concentration of $200-500 \mu \mathrm{g} \mathrm{mL} \mathrm{L}^{-1}$. It was filtered using a nylon syringe filter and injected into the HPLC instrument. Each sample was prepared in two sets $(n=2)$ and each set was evaluated in triplicate. The content of each curcuminoid was calculated from the calibration curve and total curcuminoid content was obtained from the summation of three curcuminoids.

\section{Determination of antioxidant activity}

Antioxidant activity was determined using the DPPH radical scavenging assay. Extract volumes of $50-1000 \mu \mathrm{g} \mathrm{mL} \mathrm{m}^{-1}$ were prepared using absolute ethanol as diluent. CUR, $\mathrm{DMC}$, and BDMC were also tested, with a concentration range of $1-1000 \mu \mathrm{g} \mathrm{mL} \mathrm{m}^{-1}$. The sample $(100 \mu \mathrm{L})$ was pipetted into a 96-well plate $(n=3) .100 \mu \mathrm{L}$ aliquot of the $200 \mu \mathrm{mol} \mathrm{L}-1$ DPPH ethanolic solution was then added to each well. They were incubated for $30 \mathrm{~min}$ in the dark at room temperature. The absorbance of the test sample was measured at $517 \mathrm{~nm}$ using a microplate reader (Benchmark Plus, Bio-Rad Laboratories, USA). An equal volume of absolute ethanol and DPPH ethanolic solution was used as a control. The half-maximal inhibitory concentration $I C_{50}$ was reported.

\section{Optimization}

A simplex lattice design was used in this work. Design-Expert ${ }^{\circledR}$ version 11 was used for the optimization process. Three factors, i.e., the mass ratios of C. longa, C. zedoaria, and C. aromatica rhizome powder were coded as $x_{1}, x_{2}$, and $x_{3}$, resp. The value of each factor was between 0 and $100 \%$ and the summation of all factors equals $100 \%$. Five responses, i.e., BDMC content $\left(y_{1}\right)$, DMC content $\left(y_{2}\right)$, CUR content $\left(y_{3}\right)$, total curcuminoid content $\left(y_{4}\right)$, and $I C_{50}$ value obtained from DPPH radical scavenging assay $\left(y_{5}\right)$ were determined. The contour plot of each response was created. The plots between predicted values vs. actual values and residual vs. run were produced to confirm the stability and reliability of the estimation. The statistical data, $p$-value of the model and a lack of fit of each response were reported. The desirability function was used to select the optimum conditions - the optimum mass ratio of three Curcuma rhizome powders provided the highest curcuminoid content and maximal antioxidant activity (or minimal $I C_{50}$ value).

\section{RESULTS AND DISCUSSION}

The method for analysis of curcuminoids in the rhizome of C. longa, C. zedoaria, and C. aromatica, and their mixtures was preliminary validated. The linearity parameters (linear equation and $R^{2}$ ), range and $L O D$, together with precision and accuracy data, are given in Table II. RSD values of intra- and inter-day precision were $0.1-0.2$ and $0.2-3.6 \%$, resp. In addition, accuracy was $93.4-99.8 \%$ for BDMC, 96.9-102.2 \% for DMC, and 99.0-99.2 \% for CUR. Fig. 1 shows that BDMC, DMC and CUR were eluted at the retention times of 3.95, 4.30 and $4.70 \mathrm{~min}$, resp. The selectivity ratio of DMC vs. BDMC and CUR vs. DMC was 1.11 and 1.14, resp., however, for CUR/BDMC it was 1.27. All validation data indicated the acceptable analytical performances of the method. 
C. Monton et al.: Simplex lattice design for optimization of the mass ratio of Curcuma longa L., Curcuma zedoaria (Christm.) Roscoe and Curcuma aromatica Salisb. to maximize curcuminoids content and antioxidant activity, Acta Pharm. 71 (2021) $445-457$.

Table II. Analytical performances of HPLC method

\begin{tabular}{|c|c|c|c|c|c|}
\hline \multicolumn{6}{|c|}{ Linear regression parameter } \\
\hline & \multicolumn{5}{|c|}{ Analyte } \\
\hline & \multicolumn{2}{|c|}{ BDMC } & $\mathrm{DMC}$ & \multicolumn{2}{|r|}{ CUR } \\
\hline Range $\left(\mu g \mathrm{~mL}^{-1}\right)$ & \multicolumn{2}{|c|}{$10-100$} & $10-100$ & \multicolumn{2}{|r|}{$10-100$} \\
\hline Linear equation & \multicolumn{2}{|c|}{$y=161525 x-50686$} & $y=185753 x+15028$ & \multicolumn{2}{|c|}{$y=226712 x+63963$} \\
\hline$R^{2}$ & \multicolumn{2}{|c|}{0.9992} & 0.9995 & \multicolumn{2}{|c|}{0.9993} \\
\hline$L O D\left(\mathrm{ng} \mathrm{mL}^{-1}\right)$ & \multicolumn{2}{|c|}{2.5} & 5.0 & \multicolumn{2}{|r|}{5.0} \\
\hline \multicolumn{6}{|c|}{ Precision and accuracy } \\
\hline \multirow{2}{*}{ Analyte } & \multirow{2}{*}{$\begin{array}{l}\text { Concentration } \\
\qquad\left(\mu \mathrm{g} \mathrm{mL} L^{-1}\right)\end{array}$} & \multicolumn{2}{|c|}{ Precision (RSD, \%) } & \multirow{2}{*}{$\begin{array}{c}\text { Added } \\
\text { concentration } \\
\left(\mu \mathrm{g} \mathrm{mL}^{-1}\right)\end{array}$} & \multirow[b]{2}{*}{ Accuracy (\%) } \\
\hline & & Intra-day & Inter-day & & \\
\hline \multirow{3}{*}{$\mathrm{BDMC}$} & 25 & 0.2 & 2.2 & 25 & 93.4 \\
\hline & 50 & 0.2 & 0.2 & 50 & 99.8 \\
\hline & 75 & 0.2 & 0.2 & 75 & 98.5 \\
\hline \multirow{3}{*}{$\mathrm{DMC}$} & 25 & 0.2 & 3.6 & 25 & 96.9 \\
\hline & 50 & 0.1 & 1.6 & 50 & 97.8 \\
\hline & 75 & 0.1 & 1.2 & 75 & 102.2 \\
\hline \multirow{3}{*}{ CUR } & 25 & 0.1 & 0.7 & 25 & 99.2 \\
\hline & 50 & 0.1 & 2.3 & 50 & 99.0 \\
\hline & 75 & 0.1 & 2.5 & 75 & 99.2 \\
\hline
\end{tabular}

Chromatographic parameters of the HPLC method are given in Table III.

Both individual and total curcuminoid content in rhizome powders mixture were estimated to observe their variation when different mass ratios of C. longa, C. zedoaria, and C. aromatica were applied. In this case, curcuminoids present in the extract were analyzed and calculated as curcuminoid content in the raw plant material (dried powder of rhizome). Fig. 1 shows the HPLC chromatogram of standard curcuminoids and extracts obtained under the same conditions as shown in Table I. C. longa alone (condition 1) mostly contained CUR followed by BDMC and DMC, resp. (Fig. 1a). It contained $1.06 \%$ CUR, $0.63 \%$ DMC and $0.91 \%$ BDMC; total curcuminoids content roughly $2.6 \%$. Jayaprakasha et al. (14) showed C. longa to be composed of 1.01-5.65 \% CUR, 0.83-3.36\% DMC and 0.42$2.16 \%$ BDMC. In addition, total curcuminoid content was $2.34-9.18 \%$ (14). The slight difference in the content of the curcuminoids was reported by Ali et al. (15) who stated $2.1 \%$ CUR, $0.46 \%$ DMC and $0.1 \%$ BDM, whereas Osorio-Tobón et al. (16) showed $10.2 \%$ CUR, 5.9-7.0 \% DMC and 2.1-6.1 \% BDMC in C. longa. C. longa powder filled in hard gelatin capsule contained high curcuminoids content as previously reported: $6.61-7.67 \%$ CUR, $2.76-$ $3.33 \%$ DMC and 2.64-3.47 \% BDMC (17).

C. zedoaria (condition 2) and C. aromatica (condition 3) mostly contained DMC (Figs. 1b,c). C. zedoaria contained $0.23 \%$ DMC, $0.06 \%$ BDMC and $0.04 \%$ CUR (total curcuminoids 
C. Monton et al.: Simplex lattice design for optimization of the mass ratio of Curcuma longa L., Curcuma zedoaria (Christm.) Roscoe and Curcuma aromatica Salisb. to maximize curcuminoids content and antioxidant activity, Acta Pharm. 71 (2021) $445-457$.

a)

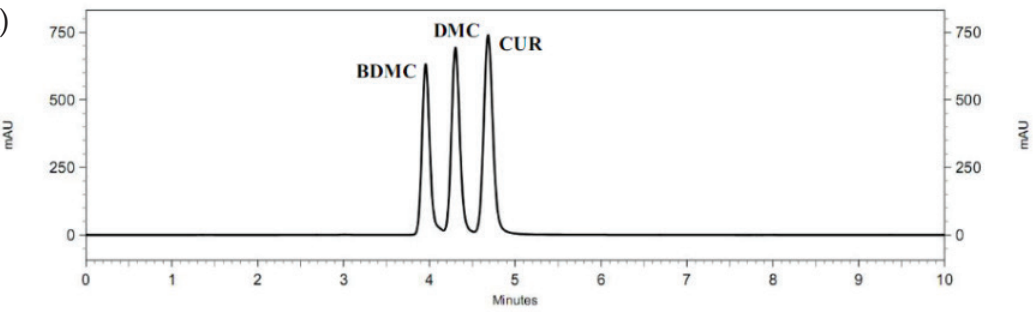

b)

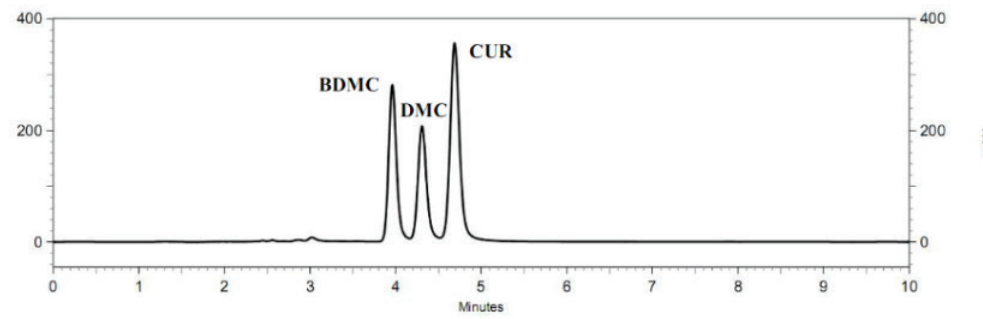

c)

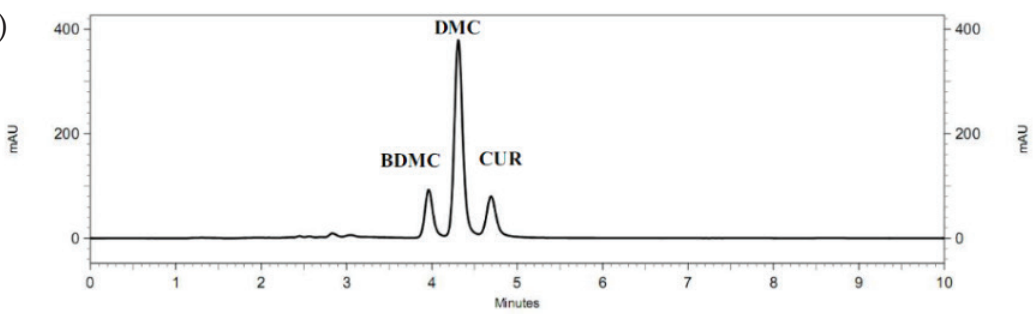

d)

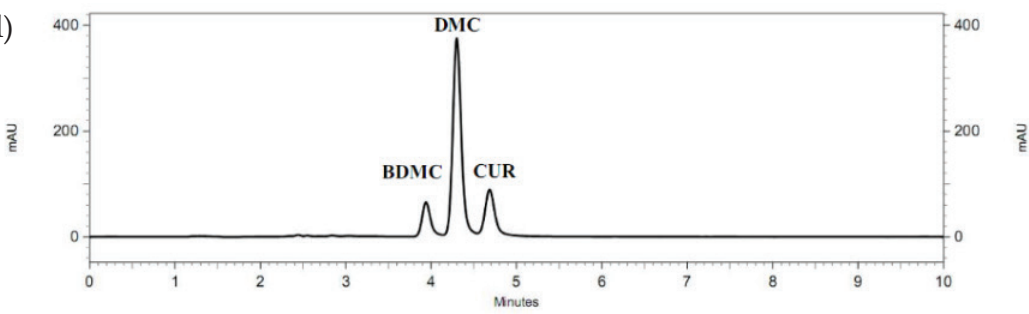

e)

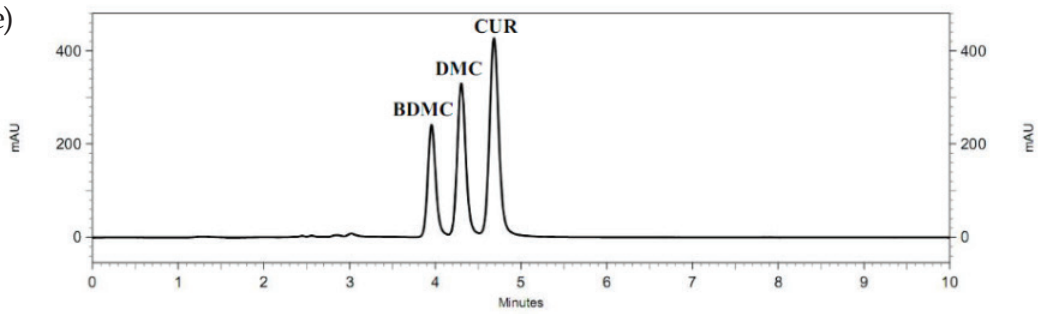

Fig. 1. HPLC chromatograms of: a) mixed standard curcuminoids $\left(50 \mu \mathrm{gL}^{-1}\right)$ and extract obtained from: b) condition $1\left(200 \mu \mathrm{g} \mathrm{mL}^{-1}\right)$, c) condition $2\left(500 \mu \mathrm{g} \mathrm{mL}^{-1}\right)$, d) condition $3\left(500 \mu \mathrm{g} \mathrm{mL}^{-1}\right)$ and e) condition $\left.10(500 \mu \mathrm{g} \mathrm{mL})^{-1}\right)$. 
C. Monton et al.: Simplex lattice design for optimization of the mass ratio of Curcuma longa L., Curcuma zedoaria (Christm.) Roscoe and Curcuma aromatica Salisb. to maximize curcuminoids content and antioxidant activity, Acta Pharm. 71 (2021) $445-457$.

Table III. Chromatographic parameters of HPLC method

\begin{tabular}{lccc}
\hline \multirow{2}{*}{ Chromatographic parameter } & \multicolumn{3}{c}{ Analyte } \\
\cline { 2 - 4 } & BDMC & DMC & CUR \\
\hline$t_{\mathrm{R}}(\mathrm{min})^{\mathrm{a}}$ & $3.95 \pm 0.01$ & $4.30 \pm 0.00_{1}$ & $4.70 \pm 0.00_{3}$ \\
Capacity factor $\left(k^{\prime}\right)^{\mathrm{b}}$ & $2.07 \pm 0.06$ & $2.30 \pm 0.00_{2}$ & $2.63 \pm 0.06$ \\
Tailing factor $\left(T_{\mathrm{f}}\right)^{\mathrm{b}}$ & $1.20 \pm 0.17$ & $1.37 \pm 0.15$ & $1.23 \pm 0.25$ \\
Number of theoretical plates $(N)^{\mathrm{b}}$ & $2196 \pm 94$ & $2252 \pm 255$ & $2369 \pm 74$ \\
Resolution $\left(R_{\mathrm{s}}\right)^{\mathrm{b}}$ & $1.50 \pm 0.26$ & $1.50 \pm 0.26$ & $1.53 \pm 0.25$ \\
Selectivity $(\alpha)^{\mathrm{b}}$ & $1.11 \pm 0.03$ & & $1.14 \pm 0.03$ \\
& - & $1.11 \pm 0.03$ & $1.27 \pm 0.03$ \\
\hline
\end{tabular}

Mean \pm SD. ${ }^{\mathrm{a}} n=3,{ }^{\mathrm{b}} n=6$.

$0.3 \%$ ). C. aromatica contained $0.43 \%$ DMC, $0.09 \%$ BDMC and $0.08 \%$ CUR (total curcuminoids content $0.6 \%$, with two times higher total curcuminoids compared with C. zedoaria, whereas C. longa had approx. 8 and 4 times, resp., higher content of total curcuminoids than the other two species. Paramapojn and Gritsanapan (18) reported that ethanolic extract of C. zedoaria rhizome contained $2.73 \%$ CUR, $7.37 \%$ DMC and $1.40 \%$ BDMC, which was close to our results: $1.02 \%$ CUR, $5.98 \%$ DMC and $1.63 \%$ BDMC. Other work of the same colleagues showed that $0.50-0.73 \%$ CUR, $0.23-1.43 \%$ DMC, $0.12-0.44 \%$ BDMC were found in C. zedoaria powder (19). C. zedoaria consisted of 0-1.5\% CUR as reported by Morishita et al. (20). However, no CUR, DMC and BDMC in C. zedoaria methanolic extract were reported in a publication by Tohda et al. (21) but $0.11 \%$ CUR with no DMC and no BDMC in C. aromatica methanolic extract. Morishita et al. (20) reported that $C$. aromatica contained $0.05-0.1 \%$ CUR estimated on a dry mass basis. However, sometimes $C$. aromatica may contain more CUR than DMC $(22,23)$. Fig. 1e shows the mixture of three plants rhizome powders in equal mass ratios (condition 10) which mostly had CUR followed by DMC and BDMC.

Our work documented that CUR exhibited the most potent antioxidant activity compared to DMC and BDMC: $I C_{50}$ values of CUR, DMC and BDMC were 38, 97, and 1,375 $\mu \mathrm{mol}$ $\mathrm{L}^{-1}$ (namely, $17.83 \pm 1.59,32.73 \pm 5.07$ and $424.10 \pm 20.40 \mu \mathrm{g} \mathrm{mL} \mathrm{L}^{-1}$ ), resp. All three curcuminoids showed good antioxidant activity. The presence of the methoxy group in CUR could increase antioxidant activity (9), so CUR showed the best antioxidant activity compared with DMC and BDMC. The $I C_{50}$ value of the standard curcuminoids varied in the literature. Abas et al. (24) reported the $I C_{50}$ values of CUR, DMC, and BDMC of 31.8, 92.5, and 104.4 $\mu \mathrm{mol} \mathrm{L}{ }^{-1}$ (or 11.7, 31.3, and $32.2 \mu \mathrm{g} \mathrm{mL}^{-1}$ ) (24) with a largely different $I C_{50}$ value of BDMC compared with our result. The low $I C_{50}$ values were reported for CUR by Borra et al. (25) of $2.9 \mu \mathrm{mol} \mathrm{L}^{-1}$ (or $1.1 \mu \mathrm{g} \mathrm{mL}^{-1}$ ) and Sökmen and Khan (26) of $22.8 \mu \mathrm{mol} \mathrm{L}^{-1}$ (or $8.4 \mu \mathrm{g} \mathrm{mL}^{-1}$ ). On the other hand, high $I C_{50}$ values were also reported: Ak and Gulcin (10) reported that CUR had $I C_{50}$ of $94.6 \mu \mathrm{mol} \mathrm{L}^{-1}$ (or $34.9 \mu \mathrm{g} \mathrm{mL}^{-1}$ ).

Regarding the plant extracts, extract obtained from the condition 1, which contained C. longa alone, exhibited the lowest $I C_{50}$ value $\left(33.83 \pm 14.05 \mu \mathrm{g} \mathrm{mL} \mathrm{m}^{-1}\right.$, equivalent to $26.01 \pm$ $1.24 \mu \mathrm{g} \mathrm{mL} \mathrm{m}^{-1}$ total curcuminoids), indicating the most potent antioxidant activity. The $I C_{50}$ of $C$. longa extract was similar to the results of the previous work $\left(33.5 \mu \mathrm{g} \mathrm{mL} \mathrm{L}^{-1}\right)$ (27). However, low $I C_{50}$ of $C$. longa extract of $9.7 \mu \mathrm{g} \mathrm{mL}^{-1}$ was reported by Zaeoung et al. (28). Further- 

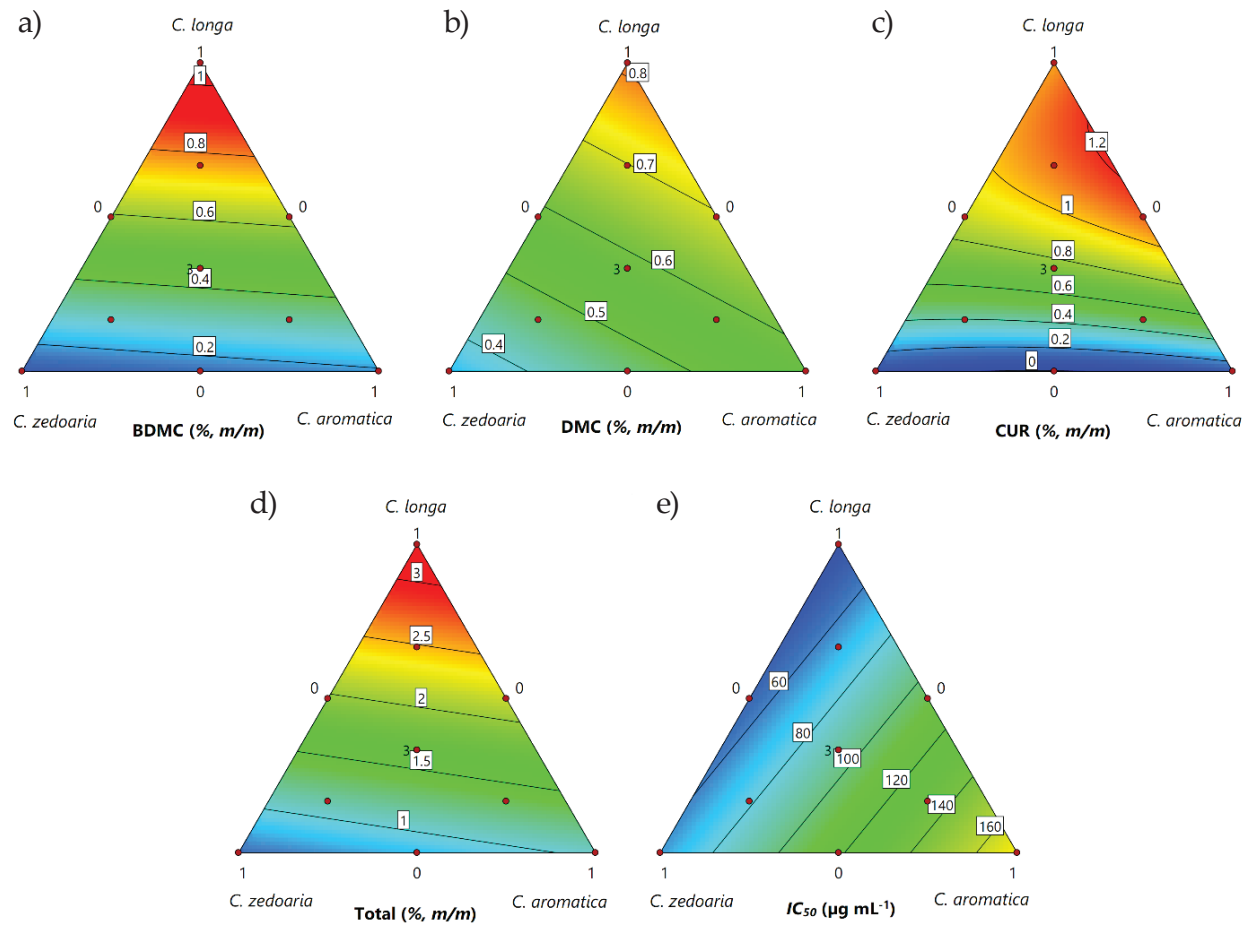

Fig. 2. Contour plots of the model conditions of: a) BDMC content, b) DMC content, c) CUR content, d) total curcuminoid content, in the plant powder mixtures, and e) $I C_{50}$ value of the extract obtained from the plant powder mixtures.

more, Tanvir et al. (29) reported that $I C_{50}$ values of $C$. longa aqueous and ethanolic extracts

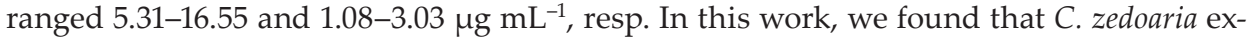
tract obtained from condition 2 and $C$. aromatica extract obtained from condition 3 had $I C_{50}$ values of $54.63 \pm 3.37$ and $138.72 \pm 4.76 \mu \mathrm{g} \mathrm{mL}^{-1}$, resp., which were equivalent to $8.63 \pm 0.96$ and $7.56 \pm 0.17 \mu \mathrm{g} \mathrm{mL}^{-1}$ total curcuminoids, resp. The other samples (extracts obtained from conditions 4-12) contained three plants in different ratios, $I C_{50}$ values ranged from approximately 40 to $200 \mu \mathrm{g} \mathrm{mL}^{-1}$. Our result was different from the previous reports. Souria et al. (30) showed that $C$. zedoaria extract had an $I C_{50}$ value of $10.60 \mu \mathrm{g} \mathrm{mL} \mathrm{L}^{-1}$, whereas Nahak and Sahu (31) reported $40 \mu \mathrm{g} \mathrm{mL} \mathrm{m}^{-1}$. They also reported an $I C_{50}$ value of $C$. aromatica extract of $120 \mu \mathrm{g} \mathrm{mL}{ }^{-1}$, which was close to the result of Srividya et al. (32) of $132.5 \mu \mathrm{g} \mathrm{mL} \mathrm{L}^{-1}$.

Fig. 2 shows the contour plots of the model conditions of curcuminoids content in dried rhizome powder and $I C_{50}$ value of the extract. The maximum BDMC, DMC and total curcuminoid content in dried rhizome powder were found when $C$. longa was used alone, whereas the minimum was found when C. zedoaria was used alone. In the case of CUR in rhizome powder, the maximum value was achieved when $C$. longa was mixed with $C$. aromatica in the mass ratio of $72: 28$, while the minimum value was found when $C$. zedoaria was mixed with $C$. aromatica in the mass ratio of 89:11. The maximum $I C_{50}$ value of the extract 
a)

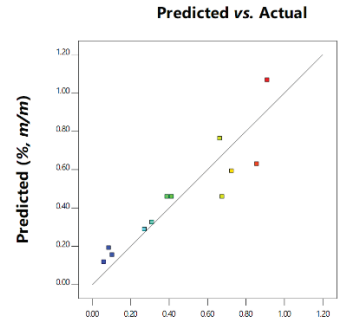

Actual $(\%, m / m)$

b)

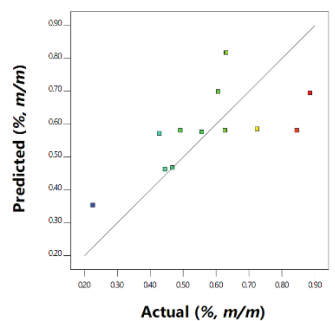

c)

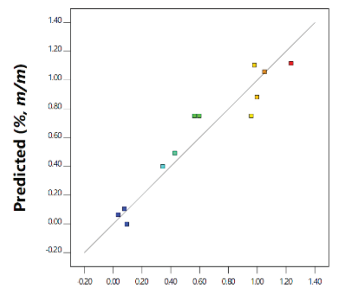

Actual $(\%, m / m)$

d)

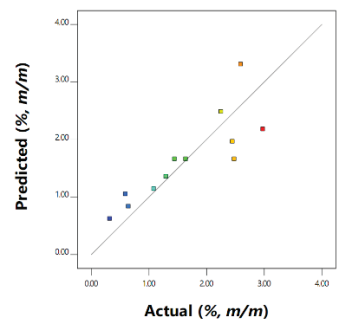

e)

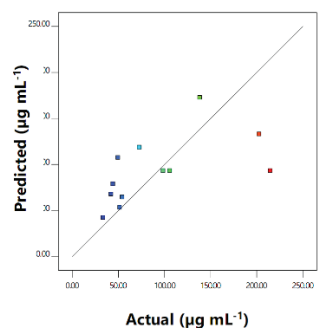

Residuals vs. Run

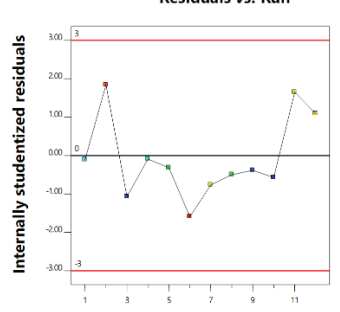

Run number
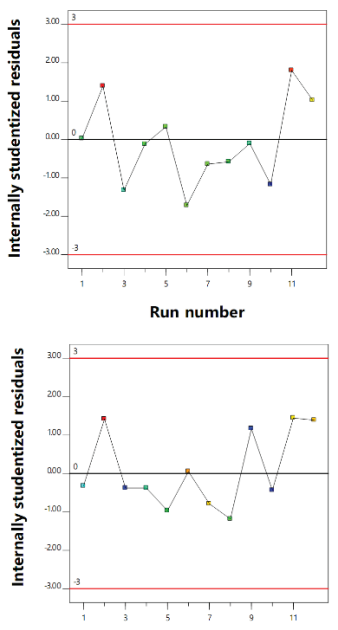

Run number

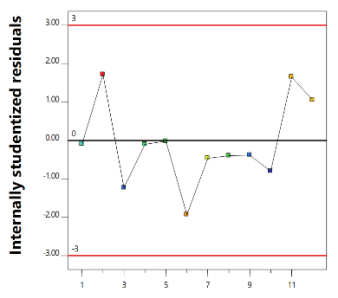

Run number

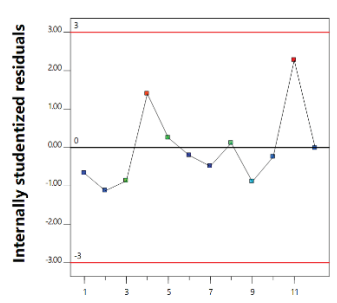

Run number

Fig. 3. Predicted vs. actual plots (left) and residual vs. run plots (right) of: a) BDMC content, b) DMC content, c) CUR content, d) total curcuminoids content, and e) $I C_{50}$ value. 
C. Monton et al.: Simplex lattice design for optimization of the mass ratio of Curcuma longa L., Curcuma zedoaria (Christm.) Roscoe and Curcuma aromatica Salisb. to maximize curcuminoids content and antioxidant activity, Acta Pharm. 71 (2021) $445-457$.

was found when $C$. aromatica was used alone and the minimum $I C_{50}$ value when $C$. longa was used alone. The results indicated that the most potent antioxidant activity was found when C. longa was used alone.

The predicted values obtained from the Design-Expert ${ }^{\circledR}$ were based on the equations shown below. Fig. 3 shows the predicted vs. actual value plots and the internally Studentized residuals vs. run number plots of the model condition of BDMC, DMC, CUR and total curcuminoids content in rhizome powder and $I C_{50}$ value of the extract. The $R^{2}$ between the predicted and actual values of model conditions of BDMC, DMC, CUR and total curcuminoids content in rhizome powder, and $I C_{50}$ value of the extract were $0.8265,0.4265,0.9183$, 0.7136 and 0.3392 , resp. The moderate to high correlation was found for BDMC, CUR and total curcuminoid content, whereas low correlation was found in DMC content and $I C_{50}$ value. The internally Studentized residuals $v$ s. run number plots displayed that the data was within the red borderline, indicating data distribution within a $95 \%$ confidence interval (CI). These results could assure the stability of the prediction. The data in Fig. 3 could approve the reliability and stability of the prediction by computer software $(33,34)$. Table IV shows the $p$-values of the model and the lack of fit of various responses. The $p$-values of experimental models of $y_{1}, y_{3}$, and $y_{4}$ were less than 0.05 indicating that model terms were significant, whereas the $p$-values of models of $y_{2}$ and $y_{5}$ were not significant. The lack of fit $p$-values of all responses was more than 0.05 implying that the lack of fit was not significant relative to the pure error. So the experimental design was not significantly affected by the error or coincidence.

Table IV. Statistical data ( $p$-value) of the model and lack of fit of each response

\begin{tabular}{ccc}
\hline \multirow{2}{*}{ Response } & \multicolumn{2}{c}{$p$-value } \\
\cline { 2 - 3 } & Model & Lack of fit \\
\hline$y_{1}$ & $0.0004^{*}$ & 0.6970 \\
$y_{2}$ & 0.0820 & 0.7042 \\
$y_{3}$ & $0.0033^{*}$ & 0.8333 \\
$y_{4}$ & $0.0036^{*}$ & 0.6218 \\
$y_{5}$ & 0.1550 & 0.7096 \\
\hline
\end{tabular}

* Statistical significance

Table V. Predicted value, actual value, percent error, and 95\% confidence interval of the prediction

\begin{tabular}{ccccc}
\hline Response & Predicted value & Actual value & Error (\%) & $\begin{array}{c}95 \% \text { CI } \\
\text { (lower-upper) }\end{array}$ \\
\hline$y_{1}(\%, m / m)$ & 1.07 & $0.91 \pm 0.10$ & -17.6 & $0.84-1.29$ \\
$y_{2}(\%, m / m)$ & 0.82 & $0.63 \pm 0.03$ & -30.2 & $0.56-1.07$ \\
$y_{3}(\%, m / m)$ & 1.05 & $1.06 \pm 0.01$ & 0.9 & $0.67-1.44$ \\
$y_{4}(\%, m / m)$ & 3.30 & $2.60 \pm 0.12$ & -26.9 & $2.43-4.17$ \\
$y_{5}\left(\mu \mathrm{g} \mathrm{mL}^{-1}\right)$ & 41.81 & $33.83 \pm 6.60$ & -23.6 & $0.00-83.62$ \\
\hline
\end{tabular}

CI - confidence interval 
C. Monton et al.: Simplex lattice design for optimization of the mass ratio of Curcuma longa L., Curcuma zedoaria (Christm.) Roscoe and Curcuma aromatica Salisb. to maximize curcuminoids content and antioxidant activity, Acta Pharm. 71 (2021) $445-457$.

The equations used for the estimation of each response are shown below:

$$
\begin{gathered}
y_{1}=1.07 x_{1}+0.12 x_{2}+0.19 x_{3} \\
y_{2}=0.82 x_{1}+0.35 x_{2}+0.57 x_{3} \\
y_{3}=1.05 x_{1}+0.06 x_{2}+0.10 x_{3}+1.28 x_{1} x_{2}+2.14 x_{1} x_{3}-0.34 x_{2} x_{3} \\
y_{4}=3.30 x_{1}+0.62 x_{2}+1.05 x_{3} \\
y_{5}=41.81 x_{1}+64.08 x_{2}+172.34 x_{3}
\end{gathered}
$$

The desirability function could be used for selecting the optimum condition. In this case, the optimum condition was the optimum mass ratio of three Curcuma rhizome powders providing the highest curcuminoid content and the maximal antioxidant activity (or minimal $I C_{50}$ value). The desirability value equal to 1 should indicate a fully desired response (35). The desirability value, obtained from the computer software Design-Expert ${ }^{\circledR}$, showed that the maximum desirability value of 0.978 was reached when $C$. longa was used alone. So, the optimum condition was approached when $C$. longa was used alone. The predicted value, actual value, percent error and range of $95 \% \mathrm{CI}$ of the prediction are shown in Table V. When the prediction value was compared with the actual value, the error of the prediction was found approximately $30 \%$ - the lowest percent error was found in $y_{3}$ of $0.9 \%$, and the highest percent error was found in $y_{2}$ of $-30.2 \%$. However, the actual value was within the lower and upper limit of the $95 \%$ confidence interval, indicating that the data obtained from the computer software were moderately accurate.

\section{CONCLUSIONS}

This work used simplex lattice design to optimize the mass ratio of three Curcuma plants' rhizomes to obtain the high curcuminoid content and antioxidant activity. Three plants, i.e., C. longa, C. zedoaria and C. aromatica, were included in the work. The CUR was the major compound found in C. longa, whereas DMC was the major compound found in C. zedoaria and C. aromatica. C. longa alone gave the highest content of BDMC and DMC. C. longa mixed with $C$. aromatica gave the highest CUR content. The lowest $I C_{50}$ value, obtained from DPPH radical scavenging assay, was found when $C$. longa was used alone. From the optimization process, $C$. longa alone reveals the highest total curcuminoid content and the most potent antioxidant activity compared with C. zedoaria, C. aromatica and their admixtures. In conclusion, the simplex lattice design could be used to optimize the mass ratio of three Curcuma plants rhizomes to obtain the maximized individual and total curcuminoid content as well as antioxidant activity with moderate accuracy.

Acknowledgements. - The authors would like to thank the College of Pharmacy, Rangsit University for facilities support. Three plant samples were authenticated by plant taxonomist, Ajarn Nirun Vipunngeun, Department of Pharmacognosy, College of Pharmacy, Rangsit University.

\section{REFERENCES}

1. Khamin Chan, in Thai Herbal Pharmacopoeia 2017, Department of Medical Sciences, the Agricultural Co-operative Federation of Thailand, Bangkok 2017, pp. 135-142. 
C. Monton et al.: Simplex lattice design for optimization of the mass ratio of Curcuma longa L., Curcuma zedoaria (Christm.) Roscoe and Curcuma aromatica Salisb. to maximize curcuminoids content and antioxidant activity, Acta Pharm. 71 (2021) $445-457$.

2. R. Agarwal, S. K. Gupta, S. Srivastava, P. Agarwal and S. S. Agrawal, Therapeutic potential of Curcuma longa, the golden spice of India, in drug discovery for ophthalmic diseases, Expert Opin. Drug Discov. 4 (2009) 147-158; https://doi.org/10.1517/13543770802668117

3. V. Soleimani, A. Sahebkar and H. Hosseinzadeh, Turmeric (Curcuma longa) and its major constituent (curcumin) as nontoxic and safe substances: Review, Phytother Res. 32 (2018) 985-995; https://doi. org/10.1002/ptr.6054

4. A. Sikha, A. Harini and L. Hegde Prakash, Pharmacological activities of wild turmeric (Curcuma aromatica Salisb): a review, J. Pharmacogn. Phytochem. 3 (2015) 1-4.

5. E. Mudge, M. Chan, S. Venkataraman and P. N. Brown, Curcuminoids in turmeric roots and supplements: Method optimization and validation, Food Anal. Meth. 9 (2016) 1428-1435; https://doi. org/10.1007/s12161-015-0326-0

6. T. Masuda, K. Hidaka, A. Shinohara, T. Maekawa, Y. Takeda and H. Yamaguchi, Chemical studies on antioxidant mechanism of curcuminoid: Analysis of radical reaction products from curcumin, J. Agric. Food Chem. 47 (1999) 71-77; https://doi.org/10.1021/jf9805348

7. T. Masuda, T. Maekawa, K. Hidaka, H. Bando, Y. Takeda and H. Yamaguchi, Chemical studies on antioxidant mechanism of curcumin: Analysis of oxidative coupling products from curcumin and linoleate, J. Agric. Food Chem. 49 (2001) 2539-2547; https://doi.org/10.1021/jf001442x

8. K. I. Priyadarsini, The chemistry of curcumin: from extraction to therapeutic agent, Molecules 19 (2014) 20091-20112; https://doi.org/10.3390/molecules191220091

9. V. P. Menon and A. R. Sudheer, Antioxidant and anti-inflammatory properties of curcumin, Adv. Exp. Med. Biol. 595 (2007) 105-125; https://doi.org/10.1007/978-0-387-46401-5_3

10. T. Ak and I. Gulcin, Antioxidant and radical scavenging properties of curcumin, Chem. Biol. Interact. 174 (2008) 27-37; https://doi.org/10.1016/j.cbi.2008.05.003

11. G. K. Jayaprakasha, L. Jaganmohan Rao and K. K. Sakariah, Antioxidant activities of curcumin, demethoxycurcumin and bisdemethoxycurcumin, Food Chem. 98 (2006) 720-724; https://doi. org/10.1016/j.foodchem.2005.06.037

12. International Conference on Harmonisation of Technical Requirements for Registration of Pharmaceuticals for Human Use, ICH Harmonised Tripartite Guideline, Validation of Analytical Procedures: Text and Methodology Q2(R1), Current Step 4 version, ICH, Geneva, November 2005; https://database.ich. org/sites/default/files/Q2\%28R1\%29\%20Guideline.pdf; last access date May 2, 2019

13. C. Monton, C. Luprasong and L. Charoenchai, Convection combined microwave drying affect quality of volatile oil compositions and quantity of curcuminoids of turmeric raw material, Rev. Bras. Farmacogn. 29 (2019) 434-440; https://doi.org/10.1016/j.bjp.2019.04.006

14. G. K. Jayaprakasha, L. Jagan Mohan Rao and K. K. Sakariah, Improved HPLC method for the determination of curcumin, demethoxycurcumin, and bisdemethoxycurcumin, J. Agric. Food Chem. 50 (2002) 3668-3672; https://doi.org/10.1021/jf025506a

15. I. Ali, A. Haque and K. Saleem, Separation and identification of curcuminoids in turmeric powder by HPLC using phenyl column, Anal. Meth. 6 (2014) 2526-2536; https://doi.org/10.1039/c3ay41987h

16. J. F. Osorio-Tobón, P. I. Carvalho, G. F. Barbero, G. C. Nogueira, M. A. Rostagno and M. A. Meireles, Fast analysis of curcuminoids from turmeric (Curcuma longa L.) by high-performance liquid chromatography using a fused-core column, Food Chem. 200 (2016) 167-174; https://doi.org/10.1016/j.foodchem.2016.01.021

17. C. Monton, L. Charoenchai, J. Suksaeree and L. Sueree, Quantitation of curcuminoid contents, dissolution profile, and volatile oil content of turmeric capsules produced at some secondary government hospitals, J. Food Drug Anal. 24 (2016) 493-499; https://doi.org/10.1016/j.jfda.2016.01.007

18. S. Paramapojn and W. Gritsanapan, Variation of curcuminoids in ethanolic extract of Curcuma zedoaria rhizomes in Thailand by HPLC, Planta Med. 73 (2007) P_227; https://doi.org/10.1055/s-2007-987008 
C. Monton et al.: Simplex lattice design for optimization of the mass ratio of Curcuma longa L., Curcuma zedoaria (Christm.) Roscoe and Curcuma aromatica Salisb. to maximize curcuminoids content and antioxidant activity, Acta Pharm. 71 (2021) $445-457$.

19. S. Paramapojn and W. Gritsanapan, Quantitative Analysis of Curcuminoids in Curcuma zedoaria Rhizomes in Thailand by HPLC Method, in International Workshop on Medicinal and Aromatic Plants (Eds. N. Chomchalow and V. Chantrasmi), Vol. 1, Chiang Mai (Thailand) 2008; ISHS Acta Hortic. 786 (2008) 169-174; https://doi.org/10.17660/ActaHortic.2008.786.18

20. T. Morishita, H. Yamaguchi, K. Degi, A. Shimizu and H. Nakagawa, Comparison of curcumin contents and antioxidative activities among turmeric species cultivated in Kanto area, Jpn. J. Crop Sci. 82 (2013) 56-62; https://doi.org/10.1626/jcs.82.56

21. C. Tohda, N. Nakayama, F. Hatanaka and K. Komatsu, Comparison of anti-inflammatory activities of six Curcuma rhizomes: A possible curcuminoid-independent pathway mediated by Curcuma phaeocaulis extract, Evid. Based Complement. Alternat. Med. 3 (2006) 255-260; https://doi.org/10.1093/ecam/nel008

22. J. Zhang, S. Jinnai, R. Ikeda, M. Wada, S. Hayashida and K. Nakashima, A simple HPLC-fluorescence method for quantitation of curcuminoids and its application to turmeric products, Anal. Sci. 25 (2009) 385-388; https://doi.org/10.2116/analsci.25.385

23. J. Lee, Y. Jung, J. H. Shin, H. K. Kim, B. C. Moon, D. H. Ryu and G. S. Hwang, Secondary metabolite profiling of Curcuma species grown at different locations using GC/TOF and UPLC/Q-TOF MS, Molecules 19 (2014) 9535-9551; https://doi.org/10.3390/molecules19079535

24. F. Abas, L. S. Hui, S. Ahmad, J. Stanslas, D. A. Israf, K. Shaari and N. H. Lajis, Biological evaluation of curcumin and related diarylheptanoids, Z. Naturforsch. C 61 (2006) 625-631; https://doi.org/10.1515/ znc-2006-9-1002

25. S. K. Borra, P. Gurumurthy, J. Mahendra, K. M. Jayamathi, C. N. Cherian and R. Chand, Antioxidant and free radical scavenging activity of curcumin determined by using different in vitro and ex vivo models, J. Med. Plants Res. 7 (2013) 2680-2690; https://doi.org/10.5897/JMPR2013.5094

26. M. Sökmen and M. Akram Khan, The antioxidant activity of some curcuminoids and chalcones, Inflammopharmacology 24 (2016) 81-86; https://doi.org/10.1007/s10787-016-0264-5

27. F. O. S. Camatari, K. H. Lopes, B. I. Valentim, J. A. Xavier, J. G. da Costa, A. E. G. Santana and M. O. F. Goulart, Antioxidant potential of flours from cereals, tubers, beans and seeds chemical profile of Curcuma longa flour, J. Nutr. Food Sci. 6 (2016) 1000483; https://doi.org/10.4172/2155-9600.1000483

28. S. Zaeoung, A. Plubrukarn and N. Keawpradub, Cytotoxic and free radical scavenging activities of Zingiberaceous rhizomes, Songklanakarin J. Sci. Technol. 27 (2005) 799-812.

29. E. M. Tanvir, M. S. Hossen, M. F. Hossain, R. Afroz, S. H. Gan, M. I. Khalil and N. Karim, Antioxidant properties of popular turmeric (Curcuma longa) varieties from Bangladesh, J. Food Qual. 2017 (2017) 8471785; https://doi.org/10.1155/2017/8471785

30. E. Souria, G. Amin, H. Farsam, H. Jalalizadeh and S. Barezi, Screening of thirteen medicinal plant extracts for antioxidant activity, Iran. J. Pharm. Res. 7 (2008) 149-154; https://doi.org/10.22037/ IJPR.2010.758

31. G. Nahak and R. K. Sahu, Evaluation of antioxidant activity in ethanolic extracts of five curcuma species, Int. Res. J. Pharm. 2 (2011) 243-248.

32. A. R. Srividya, P. Dhanabal, Parthkumar Bavadia, V. J. Vishnuvarthan and M. N. S. Kumar, Antioxidant and antidiabetic activity of Curcuma aromatica, Int. J. Res. Ayurveda Pharm. 3 (2012) 401-405.

33. S. Duangjit, L. M. Mehr, M. Kumpugdee-Vollrath and T. Ngawhirunpat, Role of simplex lattice statistical design in the formulation and optimization of microemulsions for transdermal delivery, Biol. Pharm. Bull. 37 (2014) 1948-1957; https://doi.org/10.1248/bpb.b14-00549

34. S. Duangjit, Y. Obata, H. Sano, S. Kikuchi, Y. Onuki, P. Opanasopit, T. Ngawhirunpat, Y. Maitani and K. Takayama, Menthosomes, novel ultradeformable vesicles for transdermal drug delivery: optimization and characterization, Biol. Pharm. Bull. 35 (2012) 1720-1728; https://doi.org/10.1248/bpb.b12-00343

35. M. A. Bezerra, R. E. Santelli, E. P. Oliveira, L. S. Villar and L. A. Escaleira, Response surface methodology (RSM) as a tool for optimization in analytical chemistry, Talanta 76 (2008) 965-977; https:// doi.org/10.1016/j.talanta.2008.05.019 